\title{
Common HSEQ performance improvement areas among industrial suppliers: A study of audits in a Finnish industrial cluster network
}

\author{
Henri Jounila ${ }^{1}$, Arto Reiman ${ }^{2}$, Osmo Kauppila ${ }^{3}$, Tero Savola ${ }^{4}$
}

\begin{abstract}
Supplier management is a key issue for many large industrial companies from both performance and sustainability viewpoints. In this study, a supplier audit system in a Finnish industrial cluster is examined. The cluster has created a supplier assessment procedure, and roughly 200 supplier HSEQ audits have taken place. The aim of this study is to analyse a sample of these audits to identify common improvement areas among supplier companies. Improvement suggestions taken from the audits are classified into five themes and 39 categories. The results paint a picture of the most common HSEQ improvement areas for suppliers.
\end{abstract}

\section{Introduction}

Large industrial companies face the challenging task of managing a vast network of suppliers. For example, nurturing a good safety culture for every individual and organisation working on site requires a great deal of attention on the part of industrial companies. Adopting an even broader perspective, the challenge is to ensure that supplier companies act in a responsible way, particularly in the areas of Health

\footnotetext{
${ }^{1}$ H. Jounila $(*)$

University of Oulu, Industrial Engineering and Management, Oulu, Finland e-mail: henri.jounila@oulu.fi

${ }^{2}$ A. Reiman

University of Oulu, Industrial Engineering and Management, Oulu, Finland email: arto.reiman@oulu.fi

${ }^{3}$ O. Kauppila

University of Oulu, Industrial Engineering and Management, Oulu, Finland email: osmo.kauppila@oulu.fi

${ }^{4}$ T. Savola

University of Oulu, Industrial Engineering and Management, Oulu, Finland email: tero.savola@student.oulu.fi
} 
and Safety but also in terms of Environment and Quality (HSEQ). This implies that socially responsible industrial purchasing companies must extend their management system to take stock of their suppliers' HSEQ performance (Kauppila et al. 2015; Koivupalo et al. 2015; Väyrynen et al. 2012). One practical reason for mutual interest in HSEQ performance is that both the purchaser and the supplier work together in shared workplaces. Secondly, industrial companies prefer operating with suppliers who handle their social-, economic- and environmental affairs in a sustainable manner. Stakeholders also often require this (Hofmann et al. 2014; Meixell \& Luoma 2015; Zink 2014). Purchaser-supplier HSEQ activity has been shown to create long-term positive results for both parties (Väyrynen et al. 2012). A well-developed safety management system has a positive effect on safety, as well as competitiveness (Fernández-Muñiz et al. 2009), especially in certified organisations (Vinodkumar \& Bhasi 2011). Thus, HSEQ management is justified and profitable. Generally, management systems are often intended to be simple, well-guided and efficient (Dujim et al. 2008). In this article, one simple though challenging management tool is introduced, and on the basis of this tool, the common HSEQ performance improvement areas of industrial suppliers are analysed.

A group of twelve large Finnish industrial purchasing companies have created a HSEQ cluster network over a developmental process spanning over a decade. This HSEQ cluster is open to all interested purchasing companies who meet certain criteria and accept the terms of membership. The HSEQ assessment procedure (HSEQ AP) is intended for all suppliers who want to be assessed based on their own initiative or whose assessment is requested on the purchasers' initiative. The aim of HSEQ AP is to provide feedback and thus improve the HSEQ issues and productivity of the companies. In addition, through the HSEQ AP, companies can develop their HSEQ operations and management systematically (anon, 2018). As a concrete tool, an assessment procedure for auditing supplier HSEQ capabilities has been created. In the HSEQ AP, the HSEQ performance of suppliers is assessed, audited and scored with specified criteria covering 41 topics. The assessment criteria are divided into subject areas following the EFQM Excellence Model structure. To this day, a total of around 200 HSEQ AP audits have taken place.

\section{Methods}

In this study, the database of HSEQ audits was utilised. In total, 48 audits from 2015 to 2017 were analysed in order to answer the following research question: "What kind of common improvement areas can be identified from HSEQ AP supplier audit results?" The research question was answered by collecting, analysing and classifying improvement suggestions and deviations from the audit database. 


\section{Results}

Altogether, 456 improvement suggestions and deviations (hereafter referred to as simply improvement suggestions) were gathered from the audit documents. The categorisation resulted in five main themes and 39 categories. The main themes were as follows: 1 . Operations planning and management $(n=155) ; 2$. Occupational safety management $(\mathrm{n}=113) ; 3$. Customers, stakeholders and suppliers management $(\mathrm{n}=83)$; 4. Human resource management $(\mathrm{n}=64)$; and 5. Environmental and chemical safety $(n=41)$.

\subsection{Operations planning and management}

The "Operations planning and management" theme included the most suggestions (Table 1). Within it, the largest category was the use of indicators. This included a large number of shortcomings regarding indicators and follow-up, such as the number and frequency of incident reports, sickness absences, environmental indicators, delivery reliability, reclamations and generally proactive indicators: "There was no evidence of comprehensive follow-up of indicators." "There were no incident report frequency, no LTA, no LTIF indicators." The management should better monitor and use the indicators to control their work and communicate the results: "Proactive safety indicators, e.g., safety observations, should be used and followed up on. The company should activate staff to make observations, and create processes for recording and follow-up."

Many kinds of shortcomings related to processes emerged in the "Describing the processes" category. High-level process mapping and more focus on key processes was required: "A description of the order-to-deliver process would be necessary." "It is recommended to draw up a process map showing key (core) processes." To sum up the "Principles and policies" category, more attention to creating and communicating these was requested, particularly related to safety, environment and quality principles. In other categories, the improvement suggestions concerned, for example, long-term planning and more systematic management review practices: "The business plan could not be verified... With the help of the business plan, there is a good chance of crystallising guidelines that have been jointly defined." "It is recommended that the company's key persons have a shared meeting practice in which they regularly go through the issues in accordance with the standard agenda that they agreed to together (personnel, customers, economy, development of operations, etc.)... Memos should be drawn up from the meetings... The communication of key decisions to staff should also be agreed upon." In addition, issues such as developing operations for certification (mainly quality), attention to ethical values, defining the acquisition of information and HSEQ responsibilities and creating an organisation chart were also pointed out: "It is important to draw up an organisation chart in which the most important HSEQ responsibilities are also presented." 
4 H.Jounila et al. - Common HSEQ performance improvement areas among industrial suppliers

Table 1 The Categories within "Operations planning and management"

\begin{tabular}{ll}
\hline Category & Number of improvement suggestions \\
\hline Use of indicators & 45 \\
\hline Describing the processes & 23 \\
\hline Principles and policies & 22 \\
\hline Business plan and long-term planning & 15 \\
\hline $\begin{array}{l}\text { Meetings and issues to be dealt with, manage- } \\
\text { ment activities }\end{array}$ & 15 \\
\hline Ethics and responsibility & 10 \\
\hline Certification and standards & 9 \\
\hline Defining responsibilities & 8 \\
\hline Organisation chart & 5 \\
\hline Planning products and services & 3 \\
\hline
\end{tabular}

\subsection{Occupational safety management}

The "Occupational safety management" theme consisted of 113 improvement suggestions divided into ten categories (Table 2). In the category regarding improvements to the recording and handling of accidents and incidents and communicating improvement measures, seventeen suggestions were proposed. In some cases, the related procedures were completely missing, for example: "They do not have their own procedure for investigating and handling accidents and incidents..." In the orientation category, shortcomings in the documentation and the content of the orientation, as well as in renewing the orientation, emerged: "The documentation of the orientation $¥$ the recording of the orientation into the ERP." "Based on a new person's orientation, it is necessary to draw up a signed document..."

The tools and facilities category included various suggestions relating to work equipment and facilities: "The individualised instruction signs must be affixed to the machines, including those regarding the protective equipment." "The company must draw up a list of all assets requiring an annual inspection..." "One must ensure the functionality of the emergency stop devices in equipment." Occupational safety training needs were recognised, particularly for superiors and foremen, as well as for staff: "Superiors and workers have not received safety training, except for occupational safety card training." "Superiors must be aware of their responsibilities and powers. That's why one must go to a course where these things are gone over." The improvement suggestions concerning HSEQ observations applied to the entire process, from making observations to utilising the results. Above all, the daily but also the broader identification of work hazards and risk assessment occurred within the categories related to developing safety and HSEQ risk management: "There was no evidence of the proactive identification of work hazards." "A risk mapping should be carried out to assess environmental risks and hazards." The shortcomings in occupational health and safety policy and in defining the re- 
H.Jounila et al. - Common HSEQ performance improvement areas among industrial suppliers 5 sponsibilities of superiors were emphasised in their respective categories: "Evidence of the occupational health and safety policy is requested." "It is also recommended to ensure that all safety responsibilities are individualised within the job descriptions of superiors."

Table 2 The Categories in "Occupational safety management"

\begin{tabular}{ll}
\hline Category & Number of improvement suggestions \\
\hline Procedure for incidents and accidents & 17 \\
\hline Induction & 17 \\
\hline Tools and facilities & 17 \\
\hline Occupational safety training & 13 \\
\hline HSEQ observations & 11 \\
\hline Development of safety & 10 \\
\hline HSEQ risk management & 9 \\
\hline Occupational safety and health & 7 \\
\hline Occupational safety responsibilities & 7 \\
\hline Tidiness and order & 5 \\
\hline
\end{tabular}

\subsection{Customer, stakeholder and supplier management}

The categories within the "Customer, stakeholder, and supplier management" theme are shown in Table 3. The most suggestions were found within the customer satisfaction and feedback category. These suggestions stated that customer satisfaction must be measured and followed up on and that satisfaction discussions should be organised with the customer. Customer feedback must be collected, documented, processed, and analysed; e.g., "There is no systematic way of measuring customer satisfaction." "Customer feedback is not collected systematically, and feedback is not documented or analysed." Related to the previous category, suggestions regarding reclamations were recorded as well.

Table 3 The Categories within "Customer, stakeholder and supplier management"

\begin{tabular}{ll}
\hline Category & Number of improvement suggestions \\
\hline Customer satisfaction and feedback & 33 \\
\hline Supplier selection & 15 \\
\hline Ensuring the responsibility of suppliers & 11 \\
\hline Stakeholder management & 7 \\
\hline Supplier safety & 5 \\
\hline Stakeholder communication & 5 \\
\hline Reclamations & 5 \\
\hline Monitoring the development of legislation & 2 \\
\hline
\end{tabular}

On the basis of the these categories, more systematic supplier selection and management was required: "Supplier management is memory-dependent and based on subjective experience. The company must set up a list of suppliers and principles 
for supplier selection..." "Suppliers' acceptance criteria or assessment criteria could not be verified..." "A procedure should be created for the assessment of suppliers' environmental responsibility." "A procedure must be specified to ensure supplier safety." In the categories related to stakeholders, suggestions regarding mapping stakeholders and their needs, as well as stakeholder communication, arose: "In addition to stakeholder analysis, a systematic procedure for communications and feedback collection must be set up."

\subsection{Human resource management}

Categories in the "Human resource management" theme are shown in Table 4. The category that attracted the most improvement suggestions was registry development: suppliers must create a training register and record workers' qualifications and orientations as well. The well-being at work category included several mentions of job satisfaction measurement: "There is no evidence of the systematic measurement of job satisfaction." The incentives and rewards category, as well as the initiatives, development proposals, and development discussions category, included encouragement for initiatives and the creation of an initiative system. In addition, suppliers must communicate reward principles "It is necessary to develop the initiative system and the handling process. Consider rewards." The importance of writing down decisions and communicating them, as well developing a staff backup system, emerged from four last categories.

Table 4 The Categories in "Human resource management"

\begin{tabular}{ll}
\hline Category & Number of improvement suggestions \\
\hline Registry development & 13 \\
\hline Well-being at work & 10 \\
\hline Incentives and rewards & 9 \\
\hline $\begin{array}{l}\text { Initiatives, development proposals and devel- } \\
\text { opment discussions }\end{array}$ & 9 \\
\hline Knowledge and data management & 8 \\
\hline Internal communication & 6 \\
\hline Monitoring and management of working time & 5 \\
\hline Training and development & 4
\end{tabular}

\subsection{Environmental and chemical safety}

The "Environmental and chemical safety" theme drew 41 improvement suggestions divided into three categories (Table 5). The environmental matters category contained various management issues, the most common being impact mapping: "There was no evidence of environmental management." In the Chemicals category, three areas were highlighted: chemical storage issues, shortcomings in the list of chemicals and shortcomings regarding safety data sheets, for example: "There was no person in charge appointed. There was no list of chemicals or list of safety 
data sheets." The waste sorting category included various shortcomings, such as a lack of instructions regarding waste and statistics regarding the volume of waste.

Table 5 The Categories within "Environmental and chemical safety"

\begin{tabular}{ll}
\hline Category & Number of improvement suggestions \\
\hline Environmental matters & 20 \\
\hline Chemicals & 14 \\
\hline Waste sorting & 7 \\
\hline
\end{tabular}

\section{Discussion and conclusion}

In this article, the most common improvement suggestions from HSEQ audits were considered and categorised. By analysing individual categories in more detail, more exact targets for development were determined. On the basis of this study, the following targets can be recommended and they should be considered for the development of supplier companies. Theme 1: developing and following up on indicators and utilising them as a management tool; drawing up of a process map describing the most important processes, especially the order-to-deliver process; describing and communicating principles, especially safety, environment and quality principles; drawing up a long-term plan and a business plan; organising meetings of the management and writing agendas and memos; developing operations for certification; drawing up or assessing ethical values; defining the acquisition of information and HSEQ responsibilities and drawing up the organisation chart. Theme 2: creating or improving the recording, handling and utilising accidents, incidents and HSEQ observations and communicating the appropriate measures to take in response; identifying and assessing work hazards; reviewing shortcomings in the documentation of the orientation and the content of the orientation, as well as the renewal of the orientation; enforcing occupational safety training, especially to the superiors, and defining and increasing awareness of safety responsibilities. Theme 3: measuring and following up on customer satisfaction; organising satisfaction discussions with the customer; defining, collecting, documenting, processing and examining customer feedback; paying attention to supplier selection criteria and how they affect selection; mapping stakeholders and their needs and developing stakeholder communication. Theme 4: creating a training register; creating systematic job satisfaction measurements; creating an initiative system and handling processes; improving incentives and rewards processes and communicating decision-making. Theme 5: performing environmental impact mapping; developing chemical storage and recognising shortcomings in the list of chemicals and safety data sheets.

It should be noted that in this classification system, many improvement suggestions could have been placed within several categories, but each of them was classified within only one category. The purpose of the research was to identify common improvement areas, and this was accomplished. The improvement suggestions 
8 H.Jounila et al. - Common HSEQ performance improvement areas among industrial suppliers that were the most commonly mentioned in the audit reports were represented in this research. These can be utilised in the management and control of the suppliers and supplier audits.

\section{References}

anon, 2018. HSEQ Assessment Procedure (HSEQ AP). [Online] Available at: https://www.hseq.fi/index.php?p=BrieflyinEnglish

Duijm, N.J., Fiévez, C., Gerbec, M., Hauptmanns, U. \& Konstandinidou, M., 2008. Management of health, safety and environment in process industry. Safety Science, 46(6): 908-920.

Fernández-Muñiz, B., Montes-Peón, J.M. \& Vázquez-Ordás, C.J., 2009. Relation between occupational safety management and firm performance. Safety Science, 47(7): 980-991.

Hofmann, H., Busse, C., Bode, C. \& Henke, M., 2014. Sustainability-Related Supply Chain Risks: Conceptualization and Management. Business Strategy and the Environment 23(3): 160-172.

Kauppila, O., Härkönen, J. \& Väyrynen, S., 2015. Integrated HSEQ management systems: Developments and trends. International Journal for Quality Research 9(2): 231-242.

Koivupalo, M., Junno, H. \& Väyrynen, S., 2015. Integrated management within a Finnish industrial network: steel mill case of HSEQ Assessment Procedure. In: Väyrynen, S., Häkkinen, K. \& Niskanen, T. (Eds), Integrated Occupational Safety and Health Management - Solutions and Industrial Cases: 41-67. Cham, Heidelberg, New York, Dordrecht, London: Springer, Production \& Process Engineering.

Meixell, M.J. \& Luoma, P., 2015. Stakeholder pressure in sustainable supply chain management: A systematic review. International Journal of Physical Distribution \& Logistics Management 45(1/2): 69-89.

Vinodkumar, M.N. \& Bhasi, M., 2011. A study on the impact of management system certification on safety management. Safety Science, 49(3): 498-507.

Väyrynen, S., Koivupalo, M. \& Latva-Ranta, J., 2012. A 15-year development path of actions towards an integrated management system: description, evaluation and safety effects within the process industry network in Finland. International Journal of Strategic Engineering Asset Management 1(1): 3-32.

Zink, K.J., 2014. Designing sustainable work systems: the need for a systems approach. Applied ergonomics, 45(1): 126-132. 